\title{
Fiber Fines for Fabricating Lignocellulose Films and the Effect of Lignin
}

\begin{abstract}
Mohammad Pourjafar, Amir Khosravani,* and Rabi Behrooz
Excess lignocellulose fines in some fiber processing mills cause issues and hurt product quality. To use this type of biomaterial as a resource, surplus fines can be separated and dissolved with solvents for further transformation. Therefore, 1-butyl 3-methyl imidazolium chloride ionic liquid (IL) was used as a powerful green solvent for a rapid dissolution process. However, a low degree of polymerization (DP) of the cellulose in fines and the effects of lignin content and its structure on the process and film properties are controversial subjects. This study demonstrated that the three dimensional structure of lignin did not permit the raw bagasse fines (prior to pulping) to dissolve in the IL even after several hours. However, following decomposition of the lignin structure by pulping, the fiber fines were readily dissolved. Further, all the fabricated films from the fiber fines exhibited satisfactory strength properties, despite the fact that the cellulose had a low DP. The films from bleached fiber fines showed higher tensile strength than those containing lignin, although the cellulose chain was longer and had a higher DP for the latter. Lignin resulted in reduced transparency, and higher absorption of ultraviolet radiations, but it did not affect the surface roughness of the films.
\end{abstract}

Keywords: Fiber fines; Lignocellulose film; Lignin; Ionic liquid

Contact information: Department of Wood and Paper Science and Technology, Faculty of Natural Resources, Tarbiat Modares University, 4641776489 Mazandaran, Noor, Iran;

*Corresponding author: khosravani@modares.ac.ir

\section{INTRODUCTION}

The wide application of synthetic polymers for industrial product fabrication has caused many environmental problems, as they are not biodegradable or eco-friendly, and they are increasingly accumulating in the biosphere. Moreover, dependence on fossil fuels is another challenge. Therefore, bio-based polymers and composites have attracted much attention. Bio-composite materials and films have potential use for a wide variety of applications such as environmental uses, scaffolds, food packaging, automotive industry, etc. (Pinkert et al. 2009; Abdollahi et al. 2012; Soheilmoghaddam et al. 2014).

One of the most important renewable, natural feedstocks is lignocellulose materials (Ibrahim 2002; Lateef et al. 2009; Pinkert et al. 2009). However, as most lignocellulose resources are consumed for wood products, wood-based composites, pulp and paper, and biorefining, introducing new applications can lead to more resource exploitation and further environmental damage (Lateef et al. 2009).

Therefore, developing sustainable approaches for lignocellulose material recovery and reuse is of great interest, and the effective application of lignocellulose residues is particularly important. For instance, in some fiber processing, paper manufacturing, or recycling mills, excess inactive or recycled fiber fines can reach $40 \%$ of the pulp oven-dry weight, causing problems with the process and damaging product quality (Doshi 1998; 
Jeffries and Schartman 1999; Hubbe 2002; Rahmaninia and Khosravani 2015; Steffen et al. 2016).

Fines are small fiber segments that can pass through a 200-mesh screen with nominally round hole diameters of $76 \mu \mathrm{m}$ as per TAPPI T261 cm-00 (2007). Flake-like or chunk-shaped fines have low potential to bond to improve paper strength (Motamedian et al. 2019). Therefore, surplus fiber fines can be separated for further processing as a renewable feedstock (Jeffries and Schartman 1999; Steffen et al. 2016).

However, cellulose materials are not easily dissolved in common solvents due to their numerous inter- and intra-molecular hydrogen bonds, crystalline structure, and high degrees of polymerization (Abdolkhani et al. 2013; Niroomand et al. 2016; Zhang et al. 2017). Therefore, various solvents, such as lithium chloride/1,3-dimethyl-2imidazolidinone ( $\mathrm{LiCl} / \mathrm{DMI}$ ), $\mathrm{N}$-methyl morpholine $\mathrm{N}$-oxide (NMMO), lithium chloride/N,N-dimethylacetamide (LiCl/DMAc), phosphoric acid, and urea/NaOH, were developed to prepare regenerated cellulose materials.

Unfortunately, most of the solvents cannot be widely applied due to recovery obstacles, high environmental toxicity, or detrimental side reactions (Zhang et al. 2005; Meenatchi et al. 2017). However, ionic liquids (ILs) have been proposed as suitable, environmentally friendly solvents for many chemical operations. These solvents possess very low vapor pressure, facilitating their recovery and reuse. In addition, they are nonflammable, and also chemically / thermally stable (Swatloski et al. 2002; Kilpeläinen et al. 2007; Pinkert et al. 2009; Mäki-Arvela et al. 2010; Meenatchi et al. 2017).

However, complete dissolution of wood chips from various species in the most powerful ILs has not always been achieved, even after long periods at very high temperatures (Kilpeläinen et al. 2007; Pinkert et al. 2009). Other lignocellulose materials, such as sawdust, wood fibers from thermo-mechanical pulping, bagasse fibers, and microcrystalline cellulose (MCC), have been partially or totally dissolved in ILs under mild process conditions (Fort et al. 2007; Kilpeläinen et al. 2007; Pinkert et al. 2009; MäkiArvela et al. 2010; Khosravani et al. 2018).

Moreover, it is important to clarify the effect of lignin and its structure in the dissolution of lignocellulose material in the IL. Prior to pulping, the lignin possess a compact three-dimensional structure. After pulping and bleaching, lignin breaks down and it is partially or totally removed.

The dissolution and transformation of fiber fines as a bio-polymer resource for different purposes is a controversial matter. Due to various chemical processes, such as pulping and bleaching, the degree of polymerization and crystallinity of cellulose in typical fiber fines is low. Consequently, poor mechanical properties can be expected for the resulting product. However, these qualities can be positive factors that facilitate dissolution with less viscosity and improved cellulose solution workability. In addition, the composition of fiber fines is different from that of pure cellulose raw materials, as it often contains lignin and other non-cellulose impurities that can affect cellulose recovery and reuse.

\section{EXPERIMENTAL}

\section{Materials}

De-pithed bagasse (lignocellulose residue from sugarcane processing factory), a locally available lignocellulose material, was provided by Pars Paper mill (Ahwaz, Iran). 
The raw fibrous material was pulped and bleached to prepare unbleached bagasse fiber and the bleached material. The ionic liquid, 1-butyl-3-methyl imidazolium chloride (BMIMCl) with a purity of more than $95 \%$ was purchased from Sigma-Aldrich Chemical Company (Steinheim, Germany). Other chemicals were of analytical grade, provided by local vendors, and used without further purification.

\section{Methods}

Preparation of bagasse soda pulp

For the pulping process, a 3-L cylindrical rotating digester was used. The digester was equipped with the necessary instruments for measurement and control of pressure and temperature, and it was linked through a rotary axle to ensure proper agitation. The bagasse/liquor ratio was 1:8 with an alkali charge of $22.5 \mathrm{gL}^{-1} \mathrm{NaOH}(18 \%$ based on the oven-dry weight of bagasse) for soda pulping at $170{ }^{\circ} \mathrm{C}$ for $45 \mathrm{~min}$.

Then, the resulting bagasse pulp was discharged into a 200 -mesh sieve and washed with tap water thoroughly. The Kappa number was determined according to TAPPI T236 om-99 (2007), and the evaluation of lignin content was according to TAPPI T222 om-02 (2007) with three replications. The degree of polymerization (DP) for cellulose in fiber fines was determined using the method described in the TAPPI T230 om-04 (2007) standard with a capillary viscometer at $25^{\circ} \mathrm{C}$ and using cupriethylenediamine (CED) for cellulose dissolution. Finally, the DP was calculated with Eq. 1 (Keshk 2008),

$$
D P^{0.905}=0.75[954 \log (v)-325]
$$

where $v$ is TAPPI viscosity $(\mathrm{cP})$.

\section{Precipitation of lignin from black liquor}

To prepare the lignin required for further study, the black liquor resulting from the soda pulping of bagasse in the previous stage was heated to $90{ }^{\circ} \mathrm{C}$. Then, under intensive stirring, $20 \%$ (w/w) sulfuric acid solution was added to the liquor, and the $\mathrm{pH}$ and temperature were reduced to 11 and $40{ }^{\circ} \mathrm{C}$, respectively. The filtered material was washed with distilled water. It was then diluted to $2 \%(\mathrm{w} / \mathrm{w})$ and acidified with the sulfuric acid solution to a $\mathrm{pH}$ of 2 . The precipitated lignin was washed with an acidic solution ( $\mathrm{pH}: 2$ ), air-dried, and then oven-dried in a vacuum oven at $40{ }^{\circ} \mathrm{C}$ (Lin and Dence 1992).

\section{Bleaching (delignification) of the pulp}

The bleaching process was performed to remove residual lignin according to the procedure developed by Zobel and McElwee (1966) and used for various studies (Janardhnan and Sain 2007). First, preheated distilled water (160 mL) was added to the airdried brown pulp ( $2 \mathrm{~g})$ in an Erlenmeyer flask. Then, $20 \mathrm{~mL}$ of sodium chlorite $\left(34 \mathrm{gL}^{-1}\right)$ and $20 \mathrm{~mL}$ of a prepared buffer solution $(10.5 \mathrm{~g}$ sodium hydroxide, $29 \mathrm{~mL}$ acetic acid, and $170 \mathrm{~mL}$ distilled water) were added to the flask. The flask was heated in a hot-water bath at $70{ }^{\circ} \mathrm{C}$ for $2 \mathrm{~h}$. Finally, following neutralization of the pulp by sodium sulfite, the resulting white, fully bleached fibers were thoroughly washed with distilled water.

\section{Fines and fiber fractions}

To prepare fiber fines from specified fibers of known sources for laboratory-scale evaluation, bleached (near zero-lignin content) and unbleached (2\% lignin content) fibers resulting from previous stages were ground in a small laboratory mill and then passed through a 150-mesh size (approximately 100-micron) vibratory sieve in laboratory 
conditions to obtain bleached fiber fines (BFF) and unbleached fiber fines (UFF). The same procedure was followed to prepare raw bagasse fines (RBF). To study the effect of residual lignin incorporated in the cell wall structure of UFF, the same amount of lignin (2\%) was added to BFF and the mixture was referred to as BFL.

\section{Dissolution of lignocellulose fines and preparation of the film}

The oven-dried $\left(103{ }^{\circ} \mathrm{C} \pm 2{ }^{\circ} \mathrm{C}\right.$ for $\left.24 \mathrm{~h}\right)$ lignocellulose fiber fines were mixed into hot $\left(85^{\circ} \mathrm{C}\right.$ to $\left.95^{\circ} \mathrm{C}\right) \mathrm{BMIMCL}$ liquid, at a $2 \%$ (w/w) fines: IL ratio and a $300 \mathrm{rpm}$ stirring rate under a nitrogen atmosphere for $1 \mathrm{~h}$. The resulting solution was casted on a glass plate and kept at the ambient temperature for $24 \mathrm{~h}$. Afterwards, the resulting gel was washed with distilled water once every $6 \mathrm{~h}$ for a total of 4 times to ensure complete IL removal. Eventually, the wet-produced films were mildly blotted between filter papers and dried at $60{ }^{\circ} \mathrm{C}$ for $12 \mathrm{~h}$.

\section{Optical microscope}

To visualize the development of the process, some images were taken during the initial fines dissolution stages by a MICROS N-200 optical microscope (Vienna, Austria) at 250x magnification.

\section{Characterization}

Morphological studies on the structure of the produced film specimens were performed using a Tescan MIRA3 XMU field emission scanning electron microscope (FESEM) (Tescan, Brno, Czech Republic). For preparation, the samples were frozen in liquid nitrogen, immediately snapped, and the fractured surfaces of the samples were studied.

To analyze possible chemical transformations, the infrared (IR) spectra of raw lignocellulose fines and the produced films were recorded on a SHIMADZU-8400S Fourier transform infrared (FT-IR) spectrometer (Kyoto, Japan) equipped with an attenuated total reflectance (ATR) apparatus. Thirty two scans were performed within the range of $4000 \mathrm{~cm}^{-1}$ and $400 \mathrm{~cm}^{-1}$ with a resolution of $4 \mathrm{~cm}^{-1}$.

To study the crystalline structures of cellulose material during the dissolution and preparation processes, the fines and the resulting film specimens were analyzed using a X'Pert MPD diffractometer (Philips, Eindhoven, Netherlands) with $\mathrm{Cu} \mathrm{K \alpha}$ radiation (40 $\mathrm{kV}$ and $40 \mathrm{~mA}$ ) in the range of $2 \theta=10^{\circ}$ to $50^{\circ}$ with a speed of $1.5^{\circ} / \mathrm{min}$. Then, the crystallinity indices $\left(\mathrm{CrI}_{\mathrm{S}}\right)$ were estimated with Eq. 2, according to the method of Segal et al. (1959),

$$
C r I_{\mathrm{s}}=\frac{I_{\mathrm{Max}}-I_{\mathrm{am}}}{I_{\mathrm{Max}}} \times 100
$$

where $I_{\mathrm{Max}}$ is the maximum intensity of the principal peak $\left(2 \theta=22.2^{\circ}\right)$ (200) lattice diffraction, and $I_{\mathrm{am}}$ is the intensity of diffraction attributed to the amorphous cellulose, lignin, and hemicellulose $\left(2 \theta \approx 18^{\circ}\right)$.

\section{Mechanical measurements}

To evaluate the mechanical performance of the films, tensile modulus (TM), tensile strength (TS), and elongation at break (EAB) were measured using a Perten TVT-300Xp universal testing machine (Perten Instruments, Hägersten, Sweden) according to the ASTM D882-02 (2002) standard procedure. Five rectangular samples of the films $(10 \mathrm{~mm} \times 50$ $\mathrm{mm}$ ) were prepared and their thicknesses were measured at five points. The grip separation 
distance and the constant elongation rate for the test were $30 \mathrm{~mm}$ and $10 \mathrm{~mm} / \mathrm{min}$, respectively (Niroomand et al. 2016).

\section{Contact angle (CA)}

The water droplet contact angles of the specimens were measured by applying a PG-X Goniometer dynamic contact angle analyzer (FIBRO System ab, Stockholm, Sweden), at $50 \% \mathrm{RH}, 23{ }^{\circ} \mathrm{C}$, and a droplet volume of $30 \mu \mathrm{L}$ (Khosravani et al. 2016).

\section{Water absorption (WA)}

To measure the water absorption capacity of the films, a previously published method was used that determined absorption capacity by the weight increase of the samples due to water uptake in specified periods (Lavorgna et al. 2010; Abdollahi et al. 2012; Niroomand et al. 2016). The initial weights of the $20 \mathrm{~mm} \times 20 \mathrm{~mm}$ film samples were determined by placing them in a desiccator containing fresh silica gel for approximately 3 days. Then, the samples were put in $30 \mathrm{~mL}$ of distilled water at $25{ }^{\circ} \mathrm{C}$ with a $\mathrm{pH}$ of 7 in sealed beakers. At predetermined time intervals, the WA was measured. For each measurement, the unabsorbed water on the sample surfaces was removed by blotting with a new filter paper. Finally, the WA values of the films were calculated using Eq. 3,

$$
W A(\%)=\left(W_{\mathrm{s}}-W_{i}\right) / W_{\mathrm{i}} \times 100
$$

where $W_{\mathrm{s}}$ is the secondary weight (g) of the samples following water absorption, and $W_{\mathrm{i}}$ is the initial dry weight $(\mathrm{g})$ under the above described conditions.

\section{Optical properties}

The transmittance (Tr) and opacity (Op) of the film samples were evaluated by a Lambda 25 UV-visible spectroscope (PerkinElmer Inc., Waltham, MA, USA) in the range of $200 \mathrm{~nm}$ to $800 \mathrm{~nm}$. The samples were $9 \mathrm{~mm} \times 30 \mathrm{~mm}$, and they were placed in the specified cell of the spectrophotometer directly. As a reference blank, a vacant quartz compartment was employed. Evaluation of opacity was performed at $600 \mathrm{~nm}$ and calculated according to Eq. 4 (Abdollahi et al. 2013; Atef et al. 2014),

$$
O p=A_{600} / T
$$

where $A_{600}$ is the absorbance at $600 \mathrm{~nm}$, and $T$ refers to the thickness of the film $(\mathrm{mm})$.

\section{Color evaluation}

The color parameters of the samples were analyzed by a BYK-Gardner color meter (BYK-Gardner Gmbh, Geretsried, Germany). The samples were placed on a standard white plate $\left(L^{*}=94.63, a^{*}=-0.88\right.$, and $\left.b^{*}=0.65\right)$ and the color parameters were measured. Among these parameters, $L^{*}$ indicates the lightness (0 to 100), $a^{*}$ shows (+red/-green), and $b^{*}$ is (+yellow/-blue). Therefore, the total color difference $(\Delta E)$ index was calculated with Eq. 5 (Niroomand et al. 2016):

$$
\Delta E=\sqrt{\left(\Delta L^{*}\right)^{2}+\left(\Delta a^{*}\right)^{2}+\left(\Delta b^{*}\right)^{2}}
$$

\section{Atomic force microscopy}

The surface roughness of the fabricated films was analyzed using an atomic force microscope (AFM) (NanoWizard; JPK Instruments AG, Berlin, Germany). The samples 
were placed on a glass lamella, and the measurement was taken in a $10 \mu \mathrm{m} \times 10 \mu \mathrm{m}$ area using the tapping mode. Then, the obtained root mean square (RMS) roughness data were analyzed.

\section{Statistical analysis}

To identify the statistically significant differences, an analysis of variance (ANOVA) was performed (SPSS software, SPSS Inc., Version 16.0, Chicago, USA). The obtained data were presented as mean \pm standard error, and probability values less than 0.05 were considered significant.

\section{RESULTS AND DISCUSSION}

Following the pulping process, the average pulping yield and lignin content were approximately $52 \%$ and $2 \%$, respectively. The Kappa number of the unbleached pulp samples was 16.5 .

In addition, the DP of cellulose for BFF and UFF were tested (Table 1).

Table 1. The DP of Cellulose for Unbleached and Bleached Fiber Fines

\begin{tabular}{|c|c|}
\hline Source & DP of Cellulose \\
\hline BFF & 210 \\
\hline UFF & 360 \\
\hline
\end{tabular}

Dissolution of various fines in the $I L$

The dissolution of cellulose materials in common solvents is difficult due to their highly-ordered crystalline domains, powerful intermolecular and intramolecular hydrogen bonding, and high degrees of polymerization (Song et al. 2013; Soheilmoghaddam et al. 2014).

Figure 1 shows microscopic images of lignocellulose fines in the early stages of the dissolution process. Figure 1 demonstrates that there was no observable visual development in the dissolution process of the RBF in the IL even after more than $12 \mathrm{~h}$ (Fig. 1c). In contrast, the papermaking UFF disappeared visually in less than $1 \mathrm{~h}$ in the IL. For the BFF, the process took approximately $15 \mathrm{~min}$ (Fig. 1a). This indicated that the delignification process (especially pulping) facilitated dissolution, as during pulping and bleaching, lignin, which acts as a binder between carbohydrates (hemicelluloses and cellulose) to form the complex and compact structure of lignocellulose materials (Wang et al. 2011), breaks down and is partially removed. The complex and dense structure of the original lignocellulose material between lignin, cellulose, and hemicellulose inhibits the diffusion of ionic liquid into the interior, but following pulping and bleaching, it becomes more accessible (Kilpeläinen et al. 2007).

The results in Table 1 indicate that the dissolution stage was aided by the lower lignin content and DP of cellulose in BFF than UFF due to the chemical processes in bleaching. 


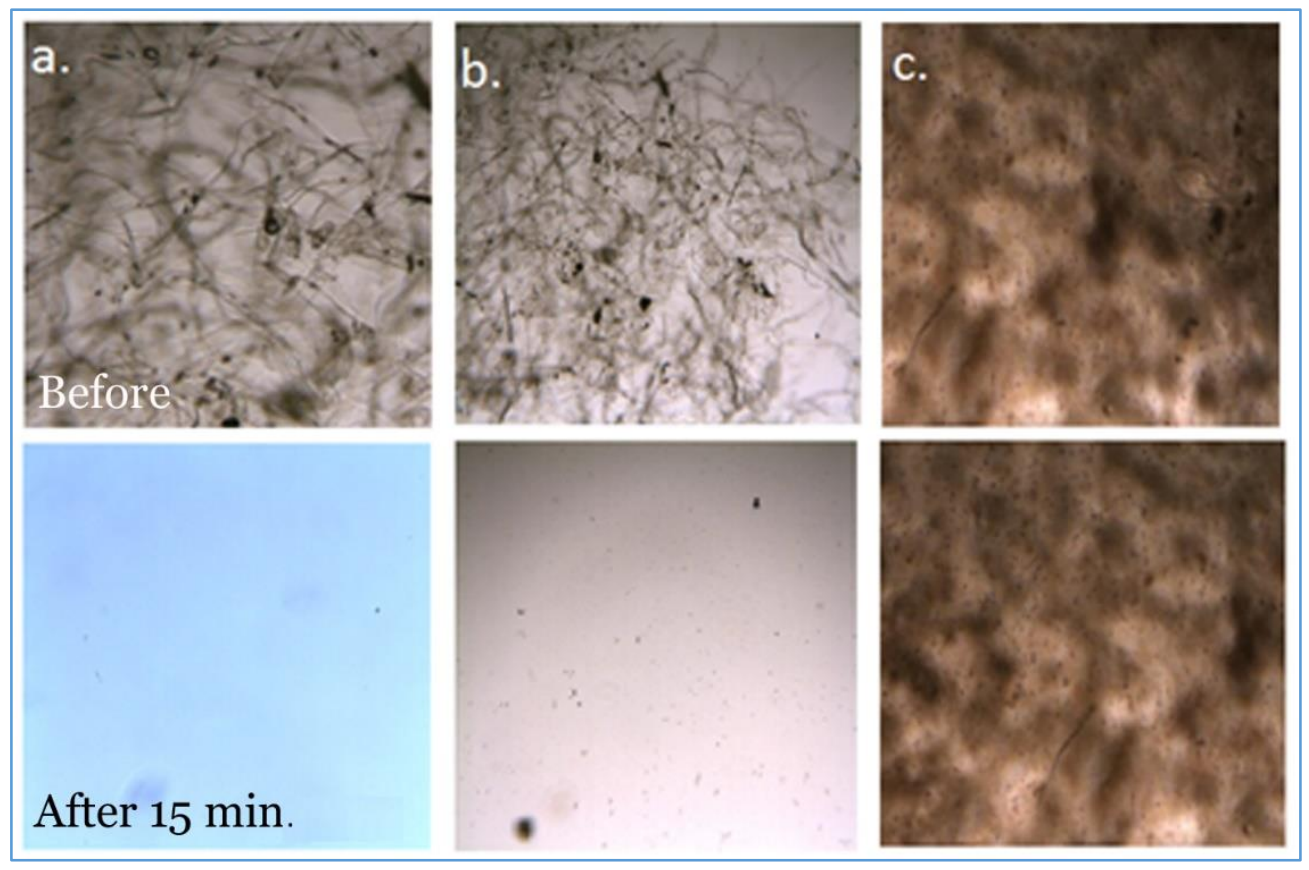

Fig. 1. Microscopic images (magnification: 250x) comparing the lignocellulose fines in the IL: a) bleached fiber fines, b) unbleached fiber fines, and c) raw bagasse fines, at the first min (top row) and 15 min after stirring in the IL (bottom row)

\section{Morphological studies}

The micrographs from the cross-section of the fabricated film specimens are presented in Fig. 2. The images show a uniform dense matrix, in which an even context with no gap is observed (Fig. 2). Therefore, the ionic liquid was able to penetrate the amorphous structures between micro/nanofibrils to dissolve the lignocellulose material. Eventually, by adding water to form a gel film, the dissolved, dispersed sections coagulated and formed an even contiguous layer. Yousefi et al. (2011) reported that the intact parts of the original nanofibrils in this structure are embedded among the regenerated sections.

Figure 2 indicates that no obvious difference was observed between the films produced from UFF, BFF, and the BFL. Especially in the case of lignin containing films, either separation of lignin or agglomeration of lignin particles in the film structure was not observed.
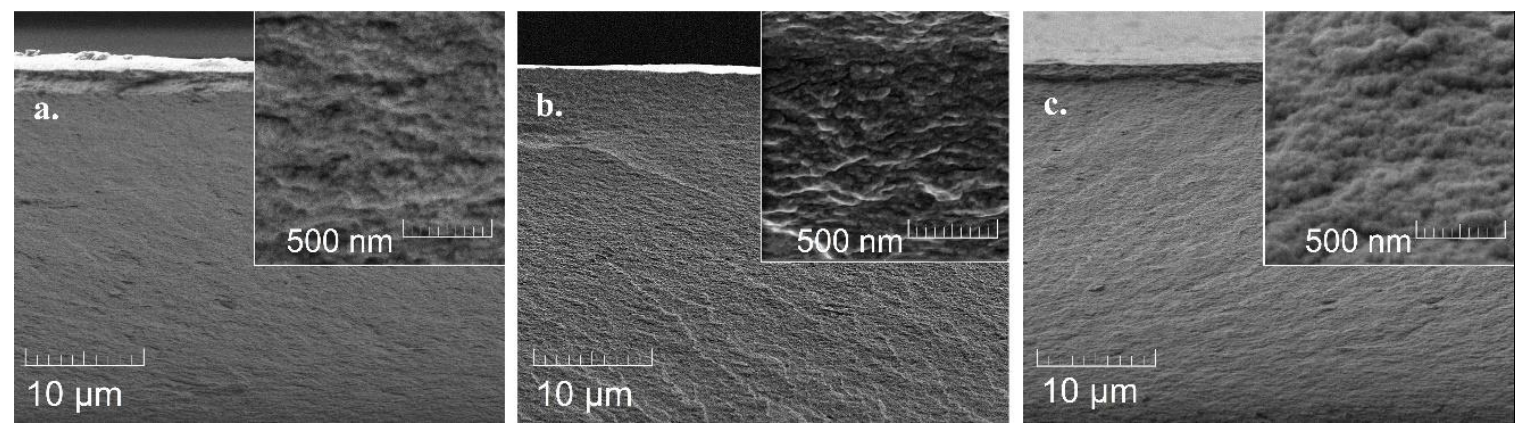

Fig. 2. The FE-SEM images (at $5 \mathrm{kX}$ and $75 \mathrm{kX}$ magnifications) from the cross-section of the fabricated film specimens (a. UFF, b. BFF, and c. BFL) 


\section{FT-IR spectroscopy}

Figure 3 compares the recorded FT-IR spectra of BFF, UFF, lignin, and those of their produced films. In all spectra, the broad band in the $3000 \mathrm{~cm}^{-1}$ to $3600 \mathrm{~cm}^{-1}$ region, and the peaks at $2850 \mathrm{~cm}^{-1}$ to $2950 \mathrm{~cm}^{-1}$ and $850 \mathrm{~cm}^{-1}$ to $1160 \mathrm{~cm}^{-1}$, were assigned to the hydroxyl $(-\mathrm{OH}), \mathrm{C}-\mathrm{H}$, and $\mathrm{C}-\mathrm{O}$ stretching vibrations, respectively. The peaks located at $1427 \mathrm{~cm}^{-1}$ and $1365 \mathrm{~cm}^{-1}$ were assigned to $\mathrm{C}-\mathrm{H} / \mathrm{CH}_{2}$ bending vibrations (Abdolkhani et al. 2013; Sohehilmoghaddam et al. 2014; Niroomand et al. 2016). For the soda lignin of bagasse, the assignments at $1596 \mathrm{~cm}^{-1}, 1512 \mathrm{~cm}^{-1}$, and $1458 \mathrm{~cm}^{-1}$ were attributed to the symmetric stretching, the asymmetric stretching of the aromatic ring, and the asymmetric C-H bending in lignin, respectively (Sammons et al. 2013; Stark et al. 2016).

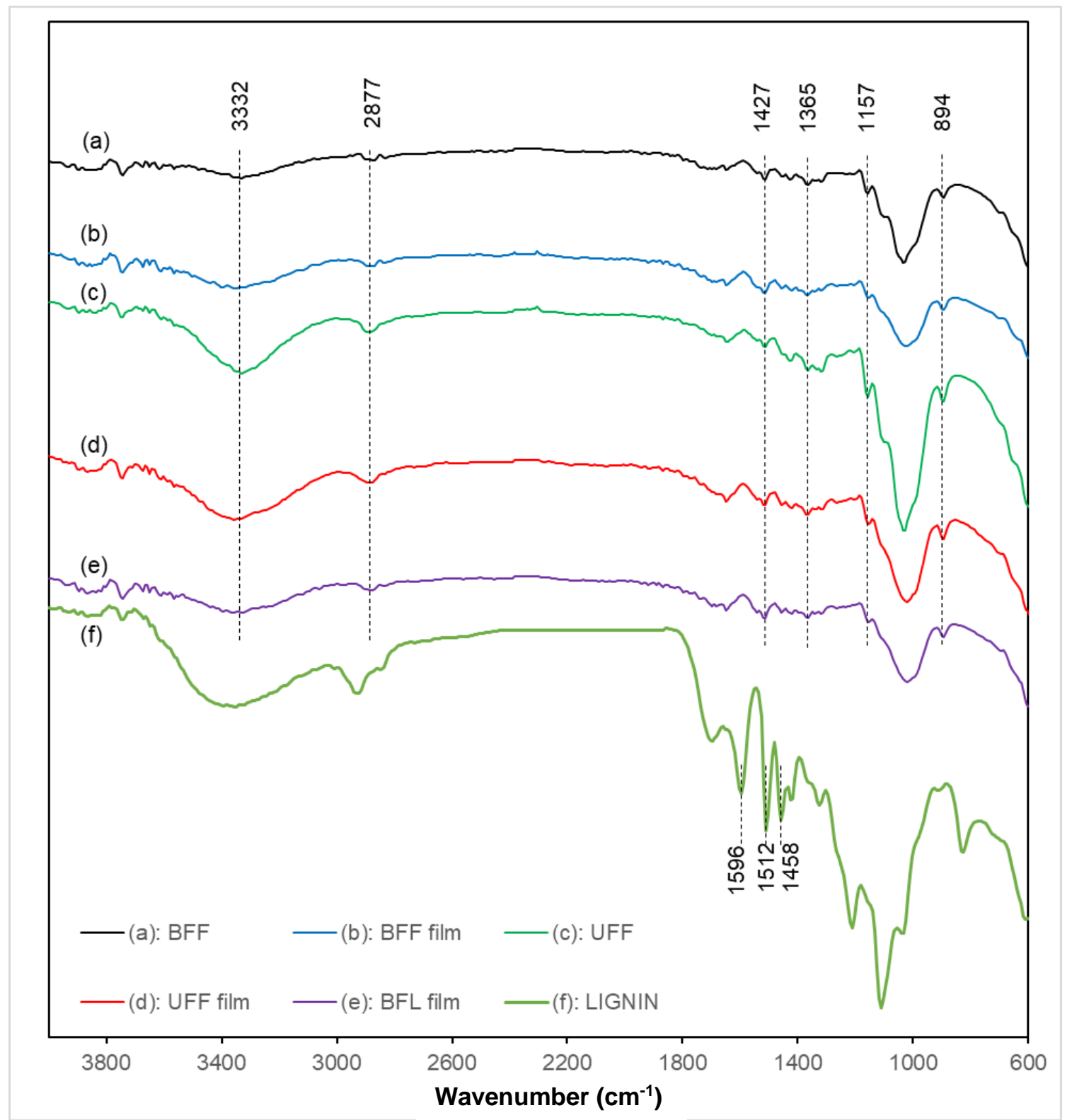

Fig. 3. The FT-IR spectra of the BFF, unbleached fiber fines, soda lignin of bagasse, and the films fabricated from these lignocellulose materials 
The similarity of the spectra (with negligible shift or intensity difference) of the regenerated film samples and their original raw cellulose materials (fiber fines) indicates that, during the fabrication of the cellulose films, hydrogen bond breaking and cellulose regeneration primarily occurs rather than cellulose derivatization and side reactions. Notably, the assignments typically indicating the presence of the ionic liquid were not observed, demonstrating that IL was successfully removed following the washing process (Niroomand et al. 2016).

\section{XRD analysis}

The X-ray diffraction patterns can present useful information about transformations in the crystalline structure of cellulose (Zugenmaier 2008; French and Santiago Cintrón 2013; French 2014). Figure 4 shows the XRD patterns for the initial lignocellulose materials compared with the fabricated film specimens. The BFF and UFF diffraction graphs exhibited peaks at $2 \theta=15.9^{\circ}, 22.5^{\circ}$, and $34.7^{\circ}$, with the most intensity observed at $2 \theta=22.5^{\circ}$. This pattern resembles the typical spectra of native cellulose (cellulose type-I) (Fort et al. 2007; Jiang et al. 2012; Niroomand et al. 2016), indicating the structure of cellulose material before treatment with the IL.

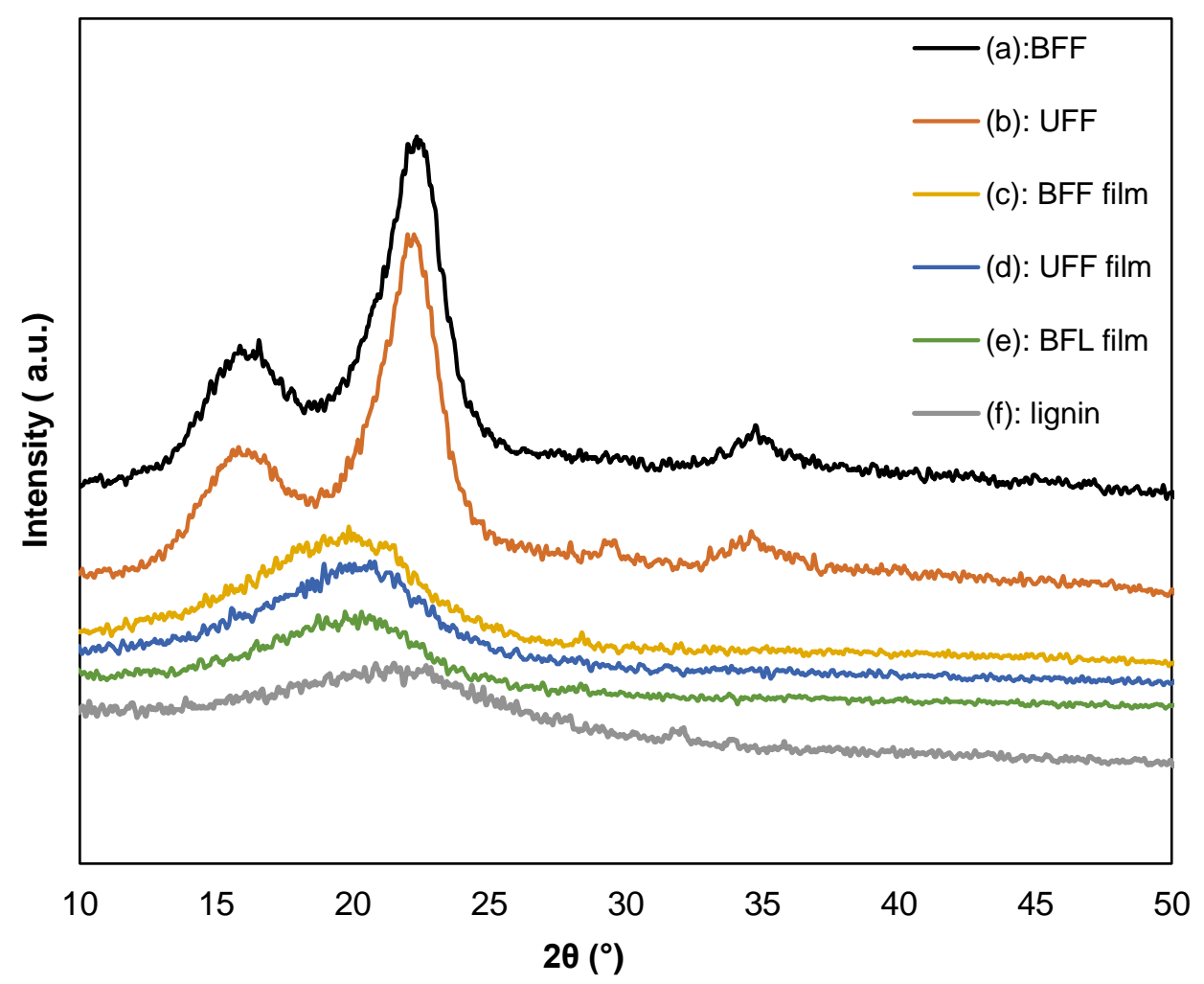

Fig. 4. The XRD diagrams of a) BFF, b) UFF, c) regenerated BFF film, d) regenerated UFF film, e) regenerated BFL film, and f) lignin

However, the XRD diagrams of the regenerated films showed only one broad peak around $2 \theta=20^{\circ}$. The broad full width at half maximum (FWHM) of the peak for the regenerated samples could be attributed to the formation of smaller regenerated cellulose crystallites and the less ordered domains in the regenerated cellulose material due to the treatment with the IL (Cheng et al. 2011; Samayam et al. 2011; Jiang et al. 2012). Further, 
as the height of the peak with the maximum intensity decreased following processing with the IL, Segal's formula (Eq. 1) demonstrated that the crystallinity index diminished from approximately $80 \%$ before dissolution to $22 \%$ following treatment with the IL and the regeneration process. These results indicated the regenerated films predominantly consisted of amorphous regions (Abdulkhani et al. 2013; Soheilmoghaddam et al. 2014). This reveals that the fiber fines were readily affected by the IL within the short treatment period, which confirms the simplicity and workability of papermaking fiber fines relative to other reports for cotton fiber, linter, or dissolving pulp (Kilpeläinen et al. 2007; Pinkert et al. 2009).

\section{Mechanical strength}

The tensile strengths (TS) and tensile moduli (TM) of the fabricated film samples were studied (Fig. 5). Figure 5 shows that BFF films had the highest TS and the lowest TM compared to the lignin-containing film specimens. This may have been due to final consequent of the opposite effect of lignin, which negatively affects bonding, versus higher DP of cellulose chain, which helps the film strength properties (Wu et al. 2009; Abdulkhani et al. 2013).

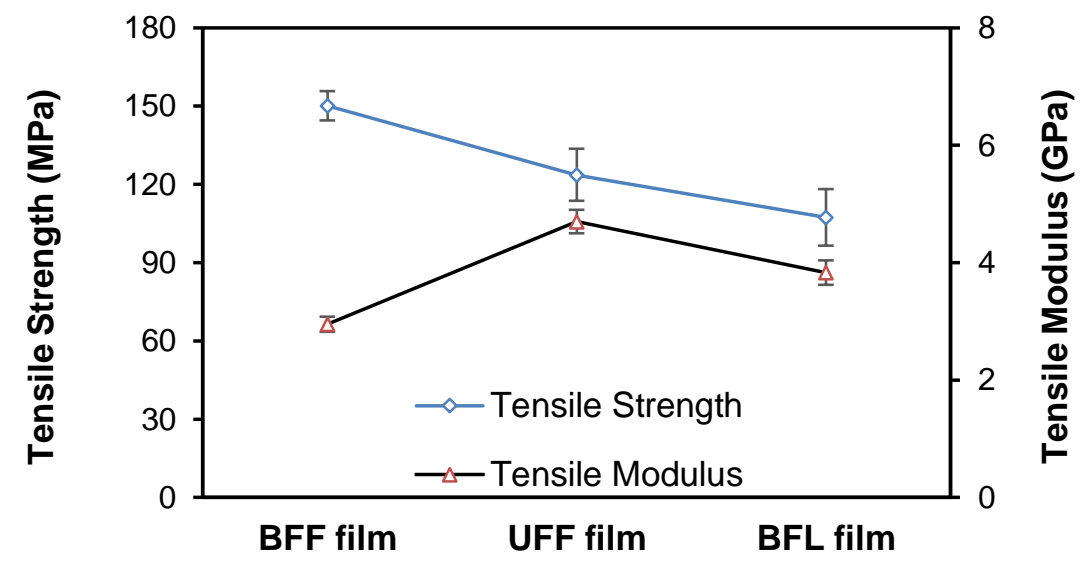

a)

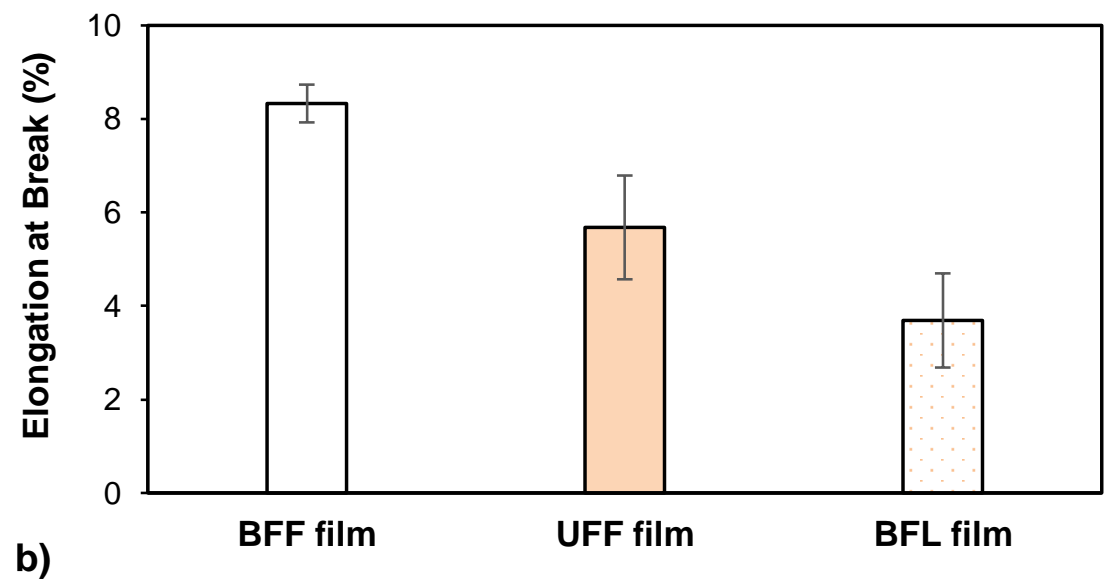

Fig. 5. Strengths properties of the films: a) tensile strength and tensile modulus, b) elongation at break 
The UFF film samples showed less TS (123.69 MPa $\pm 9.9 \mathrm{MPa})$, but the cellulose possessed higher DP among these fiber fines. The BFL films exhibited the least TS (107.35 $\mathrm{MPa} \pm 10.8 \mathrm{MPa}$ ) due to having lower DP of cellulose and added lignin. Figure 5 indicates that the lignin caused reduced elongation at break $(\mathrm{EAB})$.

\section{Surface roughness of the films}

Surface roughness data can help to quantify the smoothness of the films, which can affect other parameters (Niroomand et al. 2016). Figure 6 shows AFM illustrations of the surfaces of the films. The RMS values and the vertical scale indicating the spatial variance between the highest and lowest points are presented in Fig. 6.

The images in Fig. 6 do not indicate a clear difference between the specimens. This confirms the expectation that differences in the surface roughness of the films would not have a significant effect on other related results, such as transparency and contact angle.
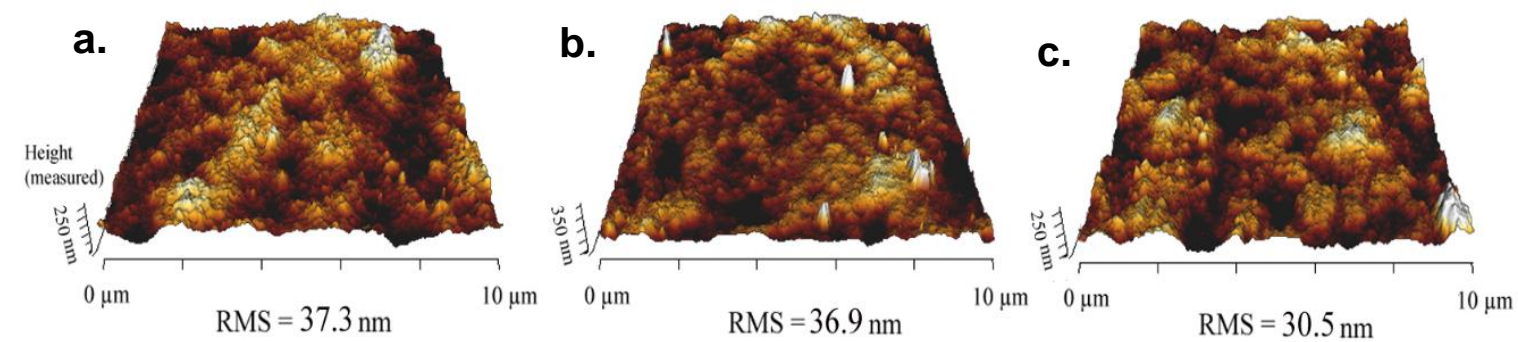

Fig. 6. The AFM images illustrating the surface roughness of a) BFF films b) UFF films, and c) BFL films

\section{Wettability and hydrophobicity}

Because the hydrophilic nature of the films could affect their application, the water absorption (WA) of the samples were studied (Fig. 7). Figure 7 demonstrates that during the first $2 \mathrm{~h}$ following immersion in water, the weight of all the film specimens increased by over $45 \%$. However, after $72 \mathrm{~h}$, all the WA diagrams reached their respective maximum values (BFL: 73\%; BFF and UFF: approximately 90\%).

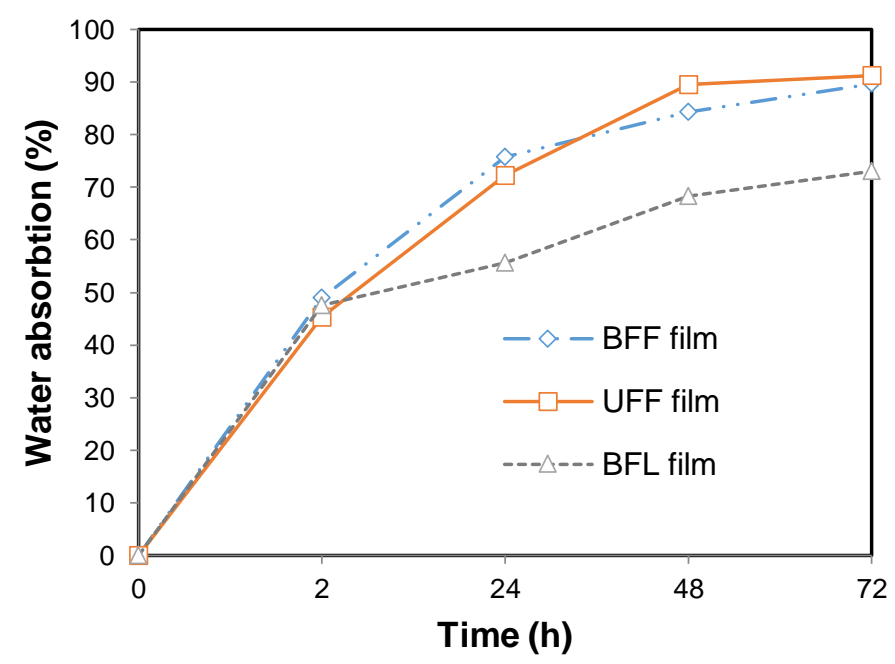

Fig. 7. The WA of the samples 
Analogous results were previously observed for regenerated cellulose film specimens (Mahmoudian et al. 2012; Soheilmoghaddam et al. 2014). Unexpectedly, the diagrams also revealed that the WA results of the UFF films more closely resembled the BFF films than the BFL samples (Fig. 7). This may be due to initial extraction of lignin and then its addition to the cellulose material, which has intensified its effects.

Table 2 presents the CA of water droplets at the collision moment and after $10 \mathrm{~s}$. The BFF films had relatively wettable hydrophilic surfaces with low CA reductions during the specified time (Mahmoudian et al. 2012). The higher CA of the UFF and BFL films was due to the presence of lignin. Simmons et al. (2011) reported that lignin diminishes the availability of hydroxyl groups and interferes with their hydrophilic effect on the film surface. Therefore, for the BFL film (with $2 \%$ lignin added), the CA increased to more than $99^{\circ}$ (relatively hydrophobic).

Table 2. The CA Data

\begin{tabular}{|c|c|c|}
\hline \multirow{2}{*}{ Samples } & \multicolumn{2}{|c|}{ CA $\left({ }^{\circ}\right)$} \\
\cline { 2 - 3 } & Collision Moment & $\mathbf{1 0}(\mathbf{s})$ \\
\hline BFF film & $69.2 \pm 4.6$ & $65.03 \pm 5.9$ \\
\hline UFF film & $82 \pm 8.8$ & $70.1 \pm 9.04$ \\
\hline BFL film & $99.9 \pm 4.9$ & $91.3 \pm 7.09$ \\
\hline
\end{tabular}

\section{Optical properties}

Because the color parameters and transparency ( $\mathrm{Tr}$ ) of a film are essential for certain applications, the relevant data is presented in Fig. 8 and Fig. 9.

Figure 8 comparatively presents the transmittance data of the films made from bleached/unbleached fiber fines between $200 \mathrm{~nm}$ and $800 \mathrm{~nm}$. Although the figure indicates similarly high $\mathrm{Tr}$ for all samples in the visible wavelength range, the lignin-containing specimens (UFF and BFL films) had lower Tr. In addition, the-lignin containing films showed more UV radiation absorption, especially for wavelengths less than $300 \mathrm{~nm}$.

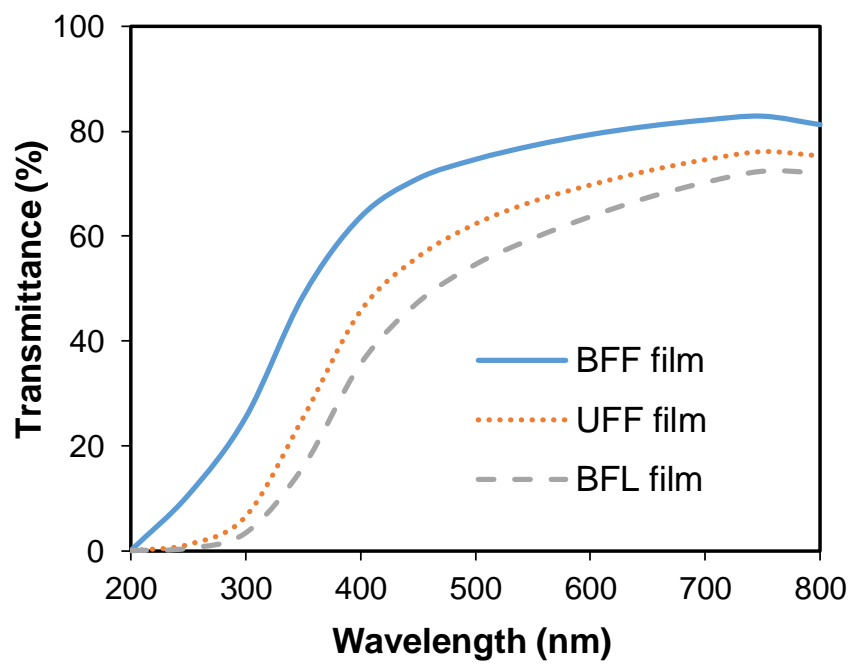

Fig. 8. Transparency of the fabricated films 
In addition, the Op test, a well-known method for the comparison of films at a specific wavelength $(600 \mathrm{~nm})$, considers film thickness (Eq. 4) (Abdollahi et al. 2012). Therefore, the thickness variations of the films could not distort the test results.

Figure 9 compares the Op of the fabricated film specimens. The Op results confirmed the results of $\operatorname{Tr}$ testing.

The appearances of the produced film specimens are compared in Fig. 10. In addition, quantitative evaluation data on the color values of the samples are presented in Table 3.

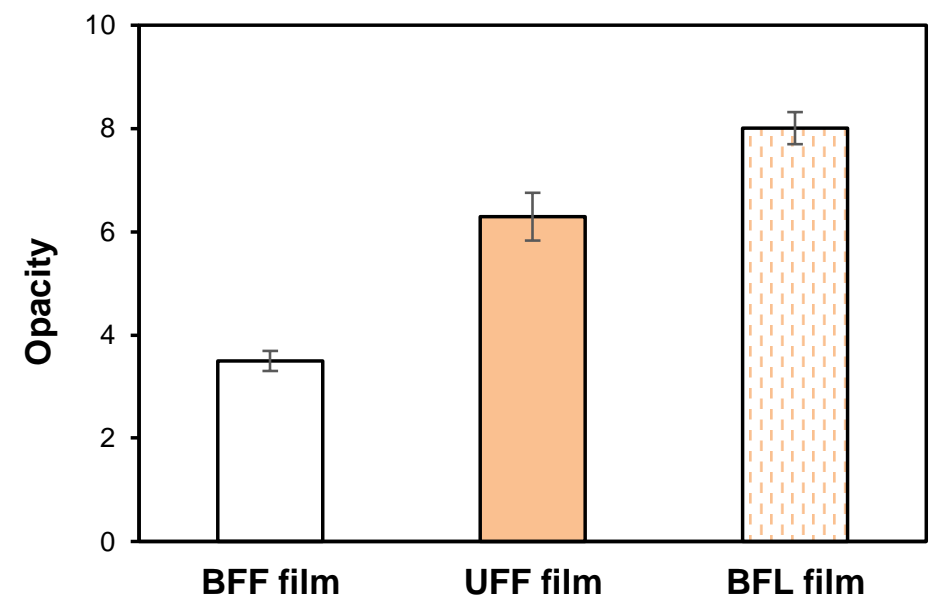

Fig. 9. Comparison of the opacity of the specimens (at $600 \mathrm{~nm}$ wavelength)

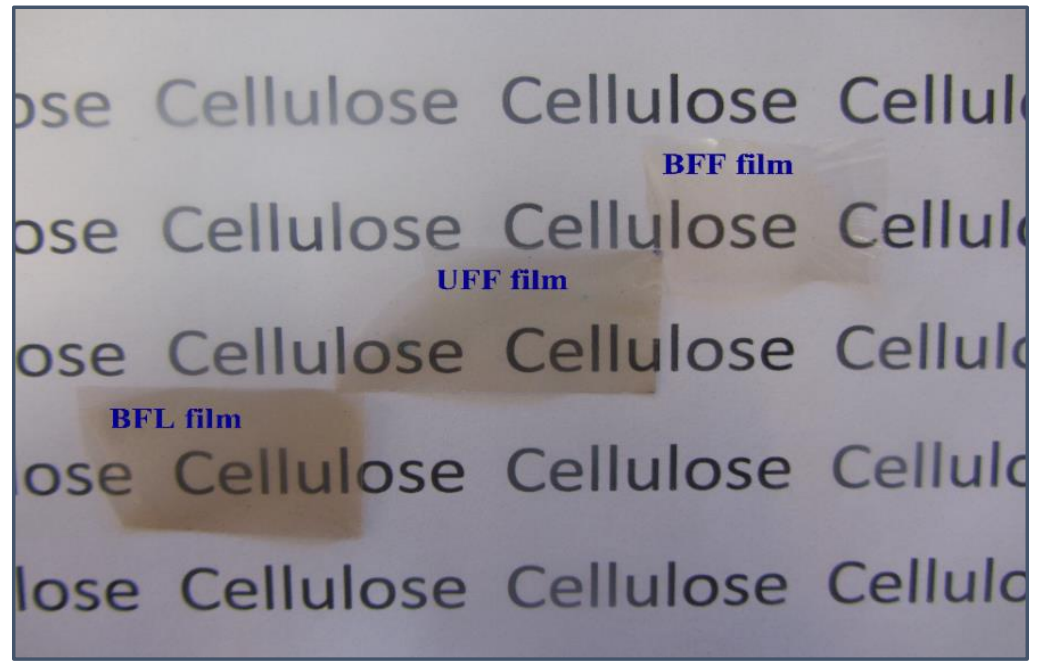

Fig. 10. The fabricated film specimens: BFF film, UFF film, and BFL film

Table 3. Color Values of the Produced Films

\begin{tabular}{|c|c|c|c|c|}
\hline $\begin{array}{c}\text { Film } \\
\text { Sample }\end{array}$ & $L^{*}$ & $a^{*}$ & $b^{*}$ & $\Delta E$ \\
\hline BFF film & $85.73 \pm 0.18$ & $-0.88 \pm 0.02$ & $8.86 \pm 0.09$ & $11.47 \pm 0.18$ \\
\hline UFF film & $80.78 \pm 0.12$ & $0.28 \pm 0.03$ & $17.24 \pm 0.08$ & $21.02 \pm 0.13$ \\
\hline BFL film & $79.85 \pm 0.34$ & $0.58 \pm 0.05$ & $17.15 \pm 0.09$ & $21.55 \pm 0.29$ \\
\hline
\end{tabular}


These data showed that the lignin-containing films (UFF and BFL) differed from the samples produced from lignin free fines $(\mathrm{BFF})$ in that they were marginally darker $\left(L^{*}\right.$ $\approx 80)$ and had tints of red $\left(a^{*} \approx+\right)$ and yellow $\left(b^{*} \approx 17\right)$.

\section{CONCLUSIONS}

1. Microscopic studies showed that all types of fiber fines (following the pulping process) were quickly dissolved in the ionic liquid. However, the compact three-dimensional structure of lignin present in the RBF prior to pulping did not allow observable dissolution in the IL, even after several hours. This indicates that papermaking fiber fines are more readily processed by the IL than the original raw lignocellulose materials. Although the DP of cellulose was low, all the films fabricated from the fiber fines exhibited satisfactory strength properties.

2. Investigating the effect of lignin in fines on the characteristics of the fabricated films indicated that all the samples possessed satisfactory mechanical properties. However, the films made of the bleached (lignin-free) fiber fines had higher tensile strength than the lignin containing ones, despite the lower DP of cellulose of the bleached fines. Further, lignin resulted in higher dynamic contact angles of the water droplets with the films. The lignin containing samples showed less transparency and higher UV absorption, but surface roughness was not significantly affected by lignin.

3. Surplus fiber fines with various lignin contents were used as resources for the fabrication of lignocellulose films, and they showed promising features for use as lignocellulose feedstocks for further processing by ILs.

\section{ACKNOWLEDGMENTS}

The authors would like to thank Tarbiat Modares University (TMU) for providing research facilities and the Iran National Science Foundation (INSF) for Grant No. 93040808.

\section{REFERENCES CITED}

Abdollahi, M., Alboofetileh, M., Behrooz, R., Rezaei, M., and Miraki, R. (2013). "Reducing water sensitivity of alginate bio-nanocomposite film using cellulose nanoparticles," International Journal of Biological Macromolecules 54, 166-173. DOI: 10.1016/j.ijbiomac.2012.12.016

Abdollahi, M., Rezaei, M., and Farzi, G. (2012). "A novel active bionanocomposite film incorporating rosemary essential oil and nanoclay into chitosan," Journal of Food Engineering 111(2), 343-350. DOI: 10.1016/j.jfoodeng.2012.02.012

Abdulkhani, A., Marvast, E. H., Ashori, A., and Karimi, A. N. (2013). "Effects of dissolution of some lignocellulosic materials with ionic liquids as green solvents on mechanical and physical properties of composite films," Carbohydrate Polymers 95(1), 57-63. DOI: 10.1016/j.carbpol.2013.02.040 
ASTM D882-02 (2002). "Standard test method for tensile properties of thin plastic sheeting," ASTM International, West Conshohocken, PA, USA.

Atef, M., Rezaei, M., and Behrooz, R. (2014). "Preparation and characterization agarbased nanocomposite film reinforced by nanocrystalline cellulose," International Journal of Biological Macromolecules 70(Supplement C), 537-544. DOI: 10.1016/j.ijbiomac.2014.07.013

Cheng, G., Varanasi, P., Li, C., Liu, H., Melnichenko, Y. B., Simmons, B. A., Kent, M. S., and Singh, S. (2011). "Transition of cellulose crystalline structure and surface morphology of biomass as a function of ionic liquid pretreatment and its relation to enzymatic hydrolysis," Biomacromolecules 12(4), 933-941. DOI:

$10.1021 / \mathrm{bm} 101240 \mathrm{z}$

Doshi, M. R. (1998). "Take care of your fines, please," Prog. Paper Recycling 7(1), 8.

Fort, D. A., Remsing, R. C., Swatloski, R. P., Moyna, P., Moyna, G., and Rogers, R. D. (2007). "Can ionic liquids dissolve wood? Processing and analysis of lignocellulosic materials with 1-n-butyl-3-methylimidazolium chloride," Green Chemistry 9(1), 6369. DOI: $10.1039 / \mathrm{b} 607614 \mathrm{a}$

French, A. D. (2014). "Idealized powder diffraction patterns for cellulose polymorphs," Cellulose 21(2), 885-896. DOI: 10.1007/s10570-013-0030-4

French, A. D., and Santiago Cintrón, M. (2013). "Cellulose polymorphy, crystallite size, and the Segal crystallinity index," Cellulose 20(1), 583-588. DOI: 10.1007/s10570012-9833-y

Hubbe, M. A. (2002). "Fines management for increased paper machine productivity," in: Proceedings of Scientific and Technical Advances in Wet End Chemistry, Barcelona, Spain, pp. 1-22.

Ibrahim, M. (2002). "Preparation of cellulose and cellulose derivative azo compounds," Cellulose 9(3/4), 337-349. DOI: 10.1023/A:1021154204053

Janardhnan, S., and Sain, M. M. (2007). "Isolation of cellulose microfibrils-An enzymatic approach,” BioResources 1(2), 176-188. DOI: 10.15376/biores.1.2.176188

Jeffries, T. W., and Schartman, R. (1999). "Bioconversion of secondary fiber fines to ethanol using counter-current enzymatic saccharification and co-fermentation," in: Applied Biochemistry and Biotechnology, B. H. Davison, and M. Finkelstein (eds.), Humana Press, Totowa, NJ, USA.

Jiang, G., Huang, W., Wang, B., Zhang, Y., and Wang, H. (2012). "The changes of crystalline structure of cellulose during dissolution in 1-butyl-3-methylimidazolium chloride," Cellulose 19(3), 679-685. DOI: 10.1007/s10570-012-9689-1

Keshk, S. M. A. S. (2008). "Homogenous reactions of cellulose from different natural sources," Carbohydrate Polymers 74(4), 942-945. DOI: 10.1016/j.carbpol.2008.05.022

Khosravani, A., Asadollahzadeh, M. T., Rahmaninia, M., Bahramifar, N., and Azadfallah, M. (2016). "The effect of external and internal application of organosilicon on hydrophobicity of recycled OCC paper," BioResources 11(4), 8257-8268. DOI: 10.15376/biores. 11.4.8257-8268

Khosravani, A., Pourjafar, M., and Behrooz, R. (2018). "The effect of lignin on processing and the properties of lignocellulose material recovered by ionic liquid," in: The Wood and Biofiber International Conference, Selangor, Malaysia, pp. 1-7. 
Kilpeläinen, I., Xie, H., King, A., Granstrom, M., Heikkinen, S., and Argyropoulos, D. S. (2007). "Dissolution of wood in ionic liquids," Journal of Agricultural and Food Chemistry 55(22), 9142-9148. DOI: 10.1021/jf071692e

Lateef, H., Grimes, S., Kewcharoenwong, P., and Feinberg, B. (2009). "Separation and recovery of cellulose and lignin using ionic liquids: A process for recovery from paper-based waste," Journal of Chemical Technology and Biotechnology 84(12), 1818-1827. DOI: 10.1002/jctb.2251

Lavorgna, M., Piscitelli, F., Mangiacapra, P., and Buonocore, G. G. (2010). "Study of the combined effect of both clay and glycerol plasticizer on the properties of chitosan films," Carbohydrate Polymers 82(2), 291-298. DOI: 10.1016/j.carbpol.2010.04.054

Mahmoudian, S., Wahit, M. U., Ismail, A. F., and Yussuf, A. A. (2012). "Preparation of regenerated cellulose/montmorillonite nanocomposite films via ionic liquids," Carbohydrate Polymers 88(4), 1251-1257. DOI: 10.1016/j.carbpol.2012.01.088

Mäki-Arvela, P., Anugwom, I., Virtanen, P., Sjöholm, R., and Mikkola, J. P. (2010). "Dissolution of lignocellulosic materials and its constituents using ionic liquids - A review," Industrial Crops and Products 32(3), 175-201. DOI: 10.1016/j.indcrop.2010.04.005

Meenatchi, B., Renuga, V., and Manikandan, A. (2017). "Cellulose dissolution and regeneration using various imidazolium based protic ionic liquids," Journal of Molecular Liquids 238, 582-588. DOI: 10.1016/j.molliq.2016.05.008

Niroomand, F., Khosravani, A., and Younesi, H. (2016). "Fabrication and properties of cellulose-nanochitosan biocomposite film using ionic liquid," Cellulose 23(2), 13111324. DOI: $10.1007 / \mathrm{s} 10570-016-0872-7$

Pinkert, A., Marsh, K. N., Pang, S., and Staiger, M. P. (2009). "Ionic liquids and their interaction with cellulose," Chemical Reviews 109(12), 6712-6728. DOI: $10.1021 / \mathrm{cr} 9001947$

Rahmaninia, M., and Khosravani, A. (2015). "Improving the paper recycling process of old corrugated container wastes," Cellulose Chemistry and Technol. 49(2), 203-208.

Samayam, I. P., Hanson, B. L., Langan, P., and Schall, C. A. (2011). "Ionic-liquid induced changes in cellulose structure associated with enhanced biomass hydrolysis," Biomacromolecules 12(8), 3091-3098. DOI: 10.1021/bm200736a

Sammons, R. J., Harper, D. P., Labbé, N., Bozell, J. J., Elder, T., and Rials, T. G. (2013). "Characterization of organosolv lignins using thermal and FT-IR spectroscopic analysis," BioResources 8(2), 2752-2767. DOI: 10.15376/biores.8.2.2752-2767

Segal, L., Creely, J. J., Martin, A. E., and Conrad, C. M. (1959). "An empirical method for estimating the degree of crystallinity of native cellulose using the x-ray diffractometer," Textile Research Journal 29(10), 786-794. DOI: $10.1177 / 004051755902901003$

Simmons, T. J., Lee, S. H., Miao, J., Miyauchi, M., Park, T. J., Bale, S. S., Pangule, R., Bult, J., Martin, J. G., and Dordick, J. S. et al. (2011). "Preparation of synthetic wood composites using ionic liquids," Wood Science and Technology 45(4), 719-733. DOI: 10.1007/s00226-010-0395-6

Soheilmoghaddam, M., Wahit, M. U., Whye, W. T., Akos, N. I., Pour, R. H., and Yussuf, A. A. (2014). "Bionanocomposites of regenerated cellulose/zeolite prepared using environmentally benign ionic liquid solvent," Carbohydrate Polymers 106(Supplement C), 326-334. DOI: 10.1016/j.carbpol.2014.02.085

Song, H. Z., Luo, Z. Q., Wang, C. Z., Hao, X. F., and Gao, J. G. (2013). "Preparation and characterization of bionanocomposite fiber based on cellulose and nano- $\mathrm{SiO}_{2}$ using 
ionic liquid," Carbohydrate Polymers 98(1), 161-167. DOI:

10.1016/j.carbpol.2013.05.079

Stark, N. M., Yelle, D. J., and Agarwal, U. P. (2016). “Techniques for characterizing lignin," in: Lignin in Polymer Composites, O. Faruk, and M. Sain (eds.), Elsevier Inc., Oxford, England, pp. 49-66.

Steffen, F., Requejo, A., Ewald, C., Janzon, R., and Saake, B. (2016). “Anaerobic digestion of fines from recovered paper processing - Influence of fiber source, lignin and ash content on biogas potential," Bioresource Technology 200, 506-513. DOI: 10.1016/j.biortech.2015.10.014

Swatloski, R. P., Spear, S. K., Holbrey, J. D., and Rogers, R. D. (2002). "Dissolution of cellulose with ionic liquids," Journal of the American Chemical Society 124(18), 4974-4975. DOI: 10.1021/ja025790m

TAPPI T222 om-02 (2007). “Acid-insoluble lignin in wood and pulp,” TAPPI Press, Atlanta, GA, USA.

TAPPI T230 om-04 (2007). "Viscosity of pulp (capillary viscometer method)," TAPPI Press, Atlanta, GA, USA.

TAPPI T236 om-99 (2007). "Kappa number of pulp," TAPPI Press, Atlanta, GA, USA.

TAPPI T261 cm-00 (2007). "Fines fraction by weight of paper stock by wet screening," TAPPI Press, Atlanta, GA, USA.

Wang, X., Li, H., Cao, Y., and Tang, Q. (2011). "Cellulose extraction from wood chip in an ionic liquid 1-allyl-3-methylimidazolium chloride (AmimCl)," Bioresource Technology 102(17), 7959-7965. DOI: 10.1016/j.biortech.2011.05.064

Wu, R.-L., Wang, X.-L., Li, F., Li, H.-Z., and Wang, Y. Z. (2009). "Green composite films prepared from cellulose, starch and lignin in room-temperature ionic liquid," Bioresource Technology 100(9), 2569-2574. DOI: 10.1016/j.biortech.2008.11.044

Yousefi, H., Nishino, T., Faezipour, M., Ebrahimi, G., and Shakeri, A. (2011). "Direct fabrication of all cellulose nanocomposite from cellulose microfibers using ionic liquid-based nanowelding," Biomacromolecules 12(11), 4080-4085. DOI: $10.1021 / \mathrm{bm} 201147 \mathrm{a}$

Zhang, H., Wu, J., Zhang, J., and He, J. (2005). "1-Allyl-3-methylimidazolium chloride room temperature ionic liquid: A new and powerful nonderivatizing solvent for cellulose," Macromolecules 38(20), 8272-8277. DOI: 10.1021/ma0505676

Zhang, J., Wu, J., Yu, J., Zhang, X., He, J., and Zhang, J. (2017). “Application of ionic liquids for dissolving cellulose and fabricating cellulose-based materials: State of the art and future trends," Materials Chemistry Frontiers 1(7), 1273-1290. DOI: 10.1039/C6QM00348F

Zobel, B., and McElwee, R. (1966). "Variation of cellulose in loblolly pine," TAPPI Journal 49(9), 383-387.

Zugenmaier, P. (2008). “Cellulose,” in: Crystalline Cellulose and Derivatives, Springer, Berlin, Germany, pp. 101-174.

Article submitted: January 27, 2020; Peer review completed: April 11, 2020; Revised version received and accepted: April 18, 2020; Published: April 27, 2020.

DOI: 10.15376/biores.15.2.4417-4433 